
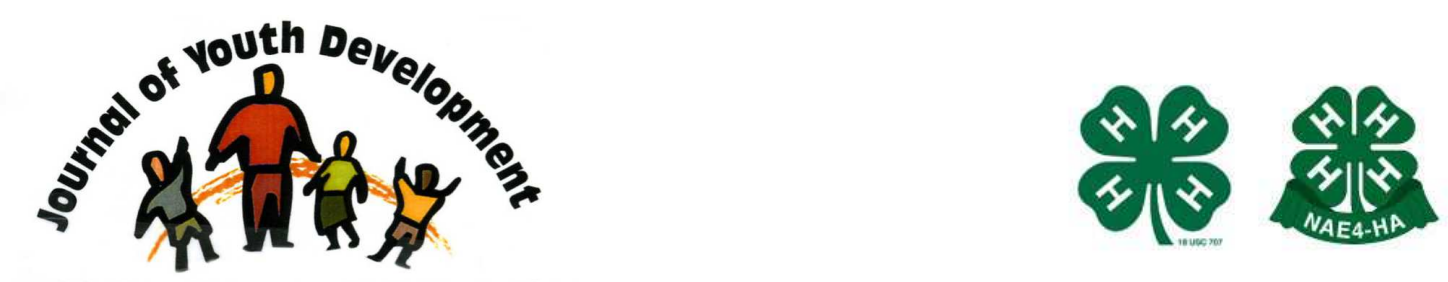

Bridging Research \& Practice

\title{
A Collaborative Effort to Address Adolescent Obesity in Primary Care
}

\author{
Meghan Bernetich \\ Smedley Wellness Center \\ Crozer-Keystone Health System \\ Chester, PA \\ Meghan.Blackman@crozer.org
}

Jennifer A. Patterson

Doctorate of Nursing Practice Program

Widener University

japatterson@mail.widener.edu 


\title{
JOURNAL OF YOUTH DEVELOPMENT \\ bridging research and practice

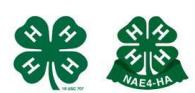

Volume 9, Number 3, Fall 2014

Article 140903RR001

\section{A Collaborative Effort to Address Adolescent Obesity in Primary Care}

\author{
Meghan Bernetich \\ Crozer-Keystone Health System \\ Jennifer A. Patterson \\ Widener University
}

\begin{abstract}
Adolescent obesity is a growing national healthcare concern. Barriers to effective treatment, such as limited time for office visits and limited reimbursement for obesity counseling, leave both patient and practitioner feeling frustrated and unsupported. This article will discuss the adolescent weight management program, Triple E: Eat, Exercise, and Enjoy. This program was created in collaboration with a pediatric primary care practice, a local university, an affiliated pediatric practice within the health system, the local middle school, and the community. Triple $E$ was developed, with minimal funding, to combat the adolescent obesity epidemic occurring in a primary care practice.
\end{abstract}

\section{Introduction}

As primary care providers, it is difficult to provide the multi-faceted, comprehensive care needed by obese and overweight youth in the fifteen or thirty minute time slot allotted for each patient visit. Holt et al. (2011), cite "lack of clinician time" as a barrier to obesity intervention (p. 16). With an increasing number of patients being too young for a factual discussion, parental involvement is paramount; however, Holt et al. (2011) also cite "lack of parental involvement" as a barrier (p. 16).

Practitioners can provide suggestions for healthy weight loss and provide hand-outs about sound nutrition and resources such as informational websites. They can discuss and treat some complications of obesity and ultimately make a referral to a nutritionist or weight management clinic. Patients are then sent on their way, unsupported, in their weight loss journey. These small interventions, performed in the primary care office, may be somewhat effective when the patient and the family are financially sound and have access to safe, reliable transportation, 
healthy food selections, and safe exercise space (such as a community center or local playground, park or gym). The HSC Foundation (2007) found that safety is a major concern for African-American and Latino parents and that environmental barriers prohibit routine exercise.

In underserved areas where patients and their families have limited economic means, limited access to fresh produce and other healthy food choices, no family car and no access to a gym or safe place to exercise (due to violence in their neighborhoods or lack of such facilities), short office interventions have limited or no effectiveness (Alm, et al., 2008; HSC Foundation, 2007)

This ineffectiveness of current interventions is evident in studies of obesity rates among underserved youth. The National Center for Health Statistics reports the following obesity data on 2-19 year olds in the United States: Gender: $16.9 \%$ are male and $15.4 \%$ are female; Racial Ethnicity: $21.6 \%$ are Hispanic or Latino, $20.6 \%$ are non-Hispanic Black, and $14.1 \%$ are nonHispanic White (Health Indicators Warehouse, 2005-2008).

Without more targeted and evidence-based interventions to help underserved, obese youth, healthcare providers are essentially helpless as children continue to gain more weight and develop associated health problems. As healthcare providers, we have become bystanders to a horrible epidemic that can (and already is) negatively affecting every aspect of our young patients' health and wellness.

\section{Program Design}

Nurse practitioners (NP) can take measures to combat this problem. In March 2012, a small, hospital-affiliated, adolescent primary care clinic operating in an underserved community, took an active stance against the obesity epidemic. The NP reached out to a local, university-based School of Nursing seeking additional nurse practitioners, interested in youth obesity, to assist with running the program. The two NPs, and two Drs. Amit and Pareen Thakral, developed their own multi-faceted weight loss program, loosely based on the Media-Smart Youth: Eat, Think, and Be Active curriculum from the National Institute of Health (NIH). The new curriculum incorporated both an educational and physical exercise component aimed at obese, adolescent females living in the local area. The group named the program Triple E: Eat, Exercise, Enjoy. The Triple $E$ program was run in order to assess whether a primary care practice, in collaboration with a university, health system, school, and local community, could successfully run a weight management program.

Triple $E$ was developed for ten participants, all obese (per BMI), adolescent females aged 11-18 years, and all living in the surrounding underserved area. The ten participants for the program were either patients of the primary care clinic where the program was run or patients from another primary care clinic within the hospital system. Program developers obtained parental consent for each participant. Participants were allowed and encouraged to bring a friend or family member of similar age also struggling with weight management. This proved to be a very effective tactic for getting participants motivated to come and participate on a regular basis and, anecdotally, also made it more fun for the participants.

During the ten-week course, participants met at the clinic weekly for one hour. The first half of each session included a didactic lesson, held in the lobby, concerning: media portrayals of foods (e.g., looking at how food ads can be very deceptive in giving nutritional information), strategies for making healthier food choices (e.g., learning to read food labels), My Plate, and exercise information (e.g., recommended length of time for exercise/day, examples of home 
exercises, tips on how to incorporate exercise into one's daily routine, etc). A program developer or community guest taught the didactic portion of each session. The second half of each session was the exercise portion; however, the practice space was too small for the size of the group. Therefore, the team sought and received permission to use the gymnasium and auditorium of the middle school for the weekly exercise sessions. Five volunteers from the community, all certified and well-experienced in their area of exercise/sport, taught Zumba, aerobics, yoga and a basketball-skills clinic. The team also ran exercise sessions which included relay races and exercise stations. Music for the exercise portion was provided via an iPod or iPhone played through speakers purchased by the team.

With an initial budget of $\$ 80$ ( $\$ 20$ from each of the four developers) the program was started. The money was used to purchase water bottles for the participants, cups and plates, craft supplies for lessons, gifts for the weekly prize baskets (hair accessories, nail polish, lip gloss), and gift cards to local retailers. The gift baskets and gift cards were awarded weekly to participants for enthusiasm, greatest effort, most weight loss, etc. A local produce distributer provided fresh fruit at the end of each session, as well as yoga mats, yoga mat carrying bags, and jump ropes; a major health insurance company donated additional yoga mats. The clinic's medical director donated additional gift cards to local retail/department stores which were also given as prizes.

\section{Program Impact}

The program developers considered Triple $E$ a solid success. Data taken from the five participants who had an attendance of $70 \%$ or greater showed a total of 39lbs lost collectively. Total weight gain as a group for those same participants was 14lbs. Observationally, the developers noticed increased self-esteem in many participants, as noted by increased eyecontact and interactions during program participation, as well as changes in body language. Of note, the participant with the greatest weight-loss had strong parental support at home.

The success of this program is attributed to the dedication of the team of developers and the motivated participants who attended regularly. Also helpful was the strong collaboration with a local university, hospital, and school, as well as the outpouring of volunteers from the community (all of whom stated their interest in continued involvement with the program).In addition, as stated earlier, encouraging each participant to bring a friend or family member who was also obese proved popular and led to better attendance rates and increased enjoyment of the program.

Due to the success of Triple $E$, the program was expanded in the fall 2012. Improvements planned for the next session of Triple $E$, based on observations by the developers of the program, feedback from participants, and research include increasing the length of the exercise portion of the session; increasing the number of sessions in the program; obtaining biometric measurements (waist, neck, and arm circumference), including parents/guardians of participants as much as possible; recruiting a nutritionist to assist participants in developing healthy meal plans; including a self-esteem scale as an outcome measure of the program; and recruiting a social worker or other counselor to provide services (including community referrals) that address the mental health issues associated with being an obese adolescent. 


\section{Discussion}

According to the evidence in current published studies, adolescent weight management programs should be multi-faceted and should include dietary modifications, physical behavior modifications, and incorporation of a parental involvement component. Individual approaches to behavioral change should be complemented with environmental and policy approaches such as building social support, modification of school meals, and changes in nutrition policies (Sharma, 2011, 215S). The team intends to seek approval from the hospital IRB for the next session of Triple $E$ to provide further research on interventions to combat childhood obesity.

\section{Implications and Summary}

Healthcare providers are not helpless bystanders to the obesity epidemic that is negatively affecting every aspect of our young patients' health. Providers can take an active role in preventing and managing obesity and its health complications. Through collaboration of local resources, effective weight management programs can be developed and run out of primary care offices with minimal funding.

Acknowledgement: The authors would like to thank Rima Himelstein, MD and Joyce Rasin, PhD, APHN$\mathrm{BC}, \mathrm{RN}$ for their guidance and support.

\section{References}

Alm, M, Soroudi, N., Wylie-Rosett, J., Isasi, C.R., Suchday, S., Rieder, J., \& Khan, U. (2008). A qualitative assessment of barriers and facilitators to achieving behavior goals among obese inner-city adolescents in a weight management program. The Diabetes Educator, 34(277). doi: $10.1177 / 0145721708314182$.

Health Indicators Warehouse. (2005-2008). Obesity in Children and Adolescents aged 2-19 years. Retrieved from: http://www.healthindicators.gov/Indicators/Obesity-in-children-and adolescents-aged-2-19-years-percent_1216/National_0/Profile/Data.

Holt, N., Schetzina, K., Dalton, W.T., Tudiver, F., Fulton-Robinson, H., \& Wu, Tiejian. (2011). Primary care practice addressing child overweight and obesity: A survey of primary care physicians at four clinics in southern Appalachia. Southern Medical Journal, 104(1), 14-19. doi: 10.1097/SMJ.0b013e3181fc968a.

HSC Foundation. (2007, February). Preventing childhood obesity in lower-income communities. Retrieved from: http://www.hscfoundation.org/aboutus/publications/initialfindingsobesityreport.pdf.

Sharma, M. (2011). Dietary education in school-based childhood obesity prevention programs. Advances in Nutrition, 2, 207S-216S. doi: 10.3945/an1111.000315.

(C) Copyright of Journal of Youth Development Bridging Research and Practice. Content may not be copied or emailed to multiple sites or posted to a listserv without copyright holder's express written permission. However, users may print, download or email articles for individual use. 